\title{
ARTIGOS
}

\section{ENTRE O CULTURAL E O SOCIAL NAS ABORDAGENS GEOGRÁFICAS}

\author{
Leonardo Luiz Silveira da Silva ${ }^{1}$
}

Instituto Federal do Norte de Minas Gerais

Enviado em 22 fev. 2020 | Aceito em 9 mar. 2021

Resumo: Este artigo contempla as grandes divergências que envolvem a abordagem material da cultura e sua desconstrução, por intermédio da avaliação da influência da virada cultural e da Nova Geografia Cultural. Sua relevância reside no fato destas divergências impactarem severamente nas modernas abordagens culturais da Geografia. Conclui-se que, para além da discussão da materialidade da cultura, a apregoada incompatibilidade entre o cultural e o social nas abordagens da Geografia Cultural é falsa, à medida que a reflexão não ontológica pode centrar-se nos efeitos sociais da materialidade mítica.

Palavras-Chave: Virada Cultural; Nova Geografia Cultural; Materialidade; Ontologia.

\section{BETWEEN THE CULTURAL AND THE SOCIAL IN GEOGRAPHICAL APPROACHES}

Abstract: This article contemplates the great divergences that involve the material approach of culture and its deconstruction, through the evaluation of the influence of the cultural turn and the New Cultural Geography. Its relevance lies in the fact that these divergences have a severe impact on modern cultural approaches to Geography. It is concluded that, in addition to discussing the materiality of culture, the incompatibility between the cultural and the social in the approaches of Cultural Geography is false, as the non-ontological reflection can focus on the social effects of mythic materiality.

Keywords: Cultural Turn; New Cultural Geography; Materiality; Ontology.

\section{ENTRE LO CULTURAL Y LO SOCIAL EN ENFOQUES GEOGRÁFICOS}

Resumen: Este artículo contempla las grandes divergencias que envuelven el enfoque material de la cultura y su deconstrucción, a través de la evaluación de la influencia del giro cultural y de la Nueva Geografía Cultural. Su relevancia radica en el hecho de que estas divergencias tienen un impacto severo en los enfoques culturales modernos de la Geografía. Se concluye que, además de la discusión sobre la materialidad de la cultura, la pretendida incompatibilidad entre lo cultural y lo social en los enfoques de la Geografía Cultural es falsa, pues la reflexión no ontológica puede enfocarse en los efectos sociales de la materialidad mítica.

Palabras clave: Giro Cultural; Nueva Geografía Cultural; Materialidad; Ontología.

1. Doutor em Geografia. Professor EBTT do Instituto Federal do Norte de Minas Gerais (IFNMG). Orcid: https://orcid.org/0000-0002-7082-529X. E-mail: leoluizbh@hotmail.com 
Introdução

Este artigo aborda uma temática não muito explorada no Brasil, mas que abarcou ricos momentos entre os anos de 1980 e 1990. Pari passu ao descrédito quanto à eficácia e o sentido da abordagem cultural saueriana e da escola de Berkeley (Duncan, 1980), surgem dois grandes movimentos ou eixos de abordagem que abrigaram divergências entre os geógrafos. De um lado, a virada cultural, que pode se autoproclamar interdisciplinar; de outro, a Nova Geografia Cultural, identificada mais detidamente com a Geografia. Estes movimentos são produtos de um zeitgeist acadêmico turbulento que se encaixa em um momento de agitação epistemológica após a efervescência neopositivista dos anos 1950 (Capel, 2013).

É necessário considerar que tanto a virada cultural quando a Nova Geografia Cultural são rótulos que possuem mais serventia didática do que representam a pretensão de dimensionar e classificar tendências. Faz mais sentido restringir as formas de pensar ao âmbito do indivíduo do que ao da coletividade (Cohen, 1993), à medida que as identidades, que dialeticamente comportam e são parcialmente expressas pelas nossas formulações mentais, são sempre acessos problemáticos da totalidade, constituindo-se de forma espacialmente fendida e temporalmente adiada (Bhabha, 2013). Isto significa considerar que as identidades são formadas por experiências de espaços desconectados e por tempos descontínuos. Cosgrove (1993), em resposta a um icônico artigo de Price e Lewis (1993), rejeitou o rótulo a ele atribuído: o de pertencimento ao rol de autores da Nova Geografia Cultural. Esta rejeição não se deu pelo seu estranhamento e eventual antagonismo frente ao corpo teórico que se convenciona compor a Nova Geografia Cultural, mas pela discordância quanto ao seu encaixe no interior de um rótulo.

Apesar de considerarmos as estruturas híbridas do pensar - e concordar que as correntes de pensamento acabam rotulando indivíduos - é possível notar claros estranhamentos entre as perspectivas teóricas, ainda que os limites de seu escopo sejam mal definidos. À grosso modo, as interseções nem sempre claras entre a virada cultural e a Nova Geografia Cultural protagonizaram divergências que ainda alimentam a abordagem cultural na Geografia. Destaca-se, a primeira vista, a crítica quanto a abordagem ontológica da cultura, ferozmente debatida entre tréplicas e réplicas que envolveram Mitchell (1995;1996), Duncan e Duncan (1996), Jackson (1996) e Cosgrove (1996), com amplas repercussões para a teoria. À segunda vista, destaca-se a discussão entre o equilíbrio que envolve a abordagem social e o academicismo cultural, à medida que as discussões sobre as desconstruções ontológicas passaram a ser entendidas, na ótica de alguns, como prejudiciais para a reflexão social.

Este artigo objetiva contemplar estas divergências, o que significa, necessariamente, lançar luz aos principais imbróglios que, por intermédio de suas reminiscências, interferem na abordagem cultural na Geografia.

\section{O quid pro quo entre Mitchell, Duncans, Jackson e Cosgrove}

A "virada cultural2" (cultural turn) enquanto fenômeno intelectual espalhou sua influência em inúmeras áreas do conhecimento, produzindo um rearranjo não somente na Geografia Cultural, mas amplamente na Geografia Humana. Manifestou-se de forma interdisciplinar, transitando por diversos departamentos das humanidades. Por diversos modos, a virada cultural até hoje "tem sido positiva

\footnotetext{
${ }^{2}$ A virada cultural possui como marca a rejeição de epistemologias positivistas e tem como ênfase os estudos sobre os significados. O pós-modernismo, pós-colonialismo e pós-estruturalismo ajudam a consolidar os seus paradigmas.
} 
para a geografia, permitindo que novas teorias críticas pudessem emergir, abrindo espaço para a abordagem de tópicos que eram considerados fora do escopo da abordagem geográfica" (VALENTINE, 2001, p.167). Como uma onda avassaladora que chegou nos anos 1970 no ambiente acadêmico americano e britânico, tornou-se fato consensual que a cultura é um fator-chave para o entendimento do arranjo econômico, político e social. Como alvo da investigação cultural consolidouse as temáticas acerca dos significados (com forte influência pós-estruturalista) e das identidades.

Nos anos 1980, consolida-se a Nova Geografia Cultural. É impossível desvincular este rótulo das influências da virada cultural, que, como vimos, possui viés interdisciplinar, assim como é notável a influência da Geografia Crítica. Enquanto a virada cultural ficou bem marcada pelo foco nas identidades, a Nova Geografia Cultural, por sua vez, focou-se no social e nas relações de poder (Corrêa e Rosendahl, 2011). De todo modo, ambos os rótulos representam um rompimento com as tradições neopositivistas que ganharam corpo nos anos 1950 e também frente aos tradicionais estudos culturais, que, no caso da geografia, são representados comumente pela escola de Berkeley que herda o legado saueriano.

Barnett (2004) chama a atenção para o seguinte fato: se por um lado os geógrafos passaram a fazer um grande esforço para incluir a discussão cultural em seus trabalhos, por outro, não se formou um consenso sobre o que a dimensão da cultura se refere. Em meio à profusão de novas metodologias aplicadas ao estudo da cultura e a multiplicação do interesse neste campo de investigação científica, grandes discussões foram travadas entre nomes consagrados da geografia.

A abordagem de Don Mitchell (1995), bastante inovadora, consistiu, além do seu caráter propositivo, como uma crítica contundente a outros geógrafos culturais prolíficos, a quem os acusou de reificar ${ }^{3}$ o conceito de cultura. Segundo Mitchell, ao trazer novos conceitos/ressignificações para a cultura, estes geógrafos permaneciam na esfera da ontologização, com a pretensão de sofisticar a reificação da cultura, todavia, sem abolir esta prática. $\mathrm{O}$ incômodo de Mitchell se manifestou frente à consolidação da Nova Geografia Cultural. No interior deste emblema, as intencionalidades de contemplação das questões sociais fazem com que a estratégia comunicativa da ontologização de categoriais tais como raça, etnia e cultura torne-se, também, uma estratégia político-ideológica. Uma vez sendo tratadas como categorias ontológicas, raça, etnia e cultura podem ser utilizadas como instrumento de luta social. Uma vez descritíveis e passíveis de delimitação, estas categorias podem, por exemplo, se tornar ferramentas para aqueles que desejam reivindicar certas políticas governamentais. Contudo, Mitchell parece crer que a ontologização é mais nociva do que benéfica: acredita que a entificação, particularmente referente à categoria cultura (mas aplicável a outras categorias), "é uma imposição, um processo de nomear e definir que expõe o poder das classes dominantes e que permite a desmitificação de movimentos oposicionais" (MITCHEL, 1999, p.47).

Uma leitura incompleta ou apressada de Mitchell (1999) pode levar a crer que o autor é desprovido de sensibilidade social. Este, definitivamente, não é o caso de sua abordagem. Em uma conclusão importante, após criticar a ontologização da cultura, sugere que uma agenda relevante para a Geografia Cultural é a compreensão de como os grupos poderosos operacionalizam historicamente a noção de cultura. Deste modo, é crucial conceber que a crítica quanto à reificação da cultura não é o mesmo que defender o fim das manifestações culturais, assim como à crítica quanto à reificação da raça não é o mesmo que assegurar que o racismo não existe. A desconsideração dessas diferenças nem tão sutis alimentam a ira de grupos militantes direcionada

\footnotetext{
${ }^{3}$ O sentido da reificação, termo que será utilizado outras vezes no texto deste artigo, refere-se às duas dimensões quando aplicado à cultura: a primeira, diz respeito à delimitação conceitual do que seja cultura; a segunda, a uma descrição da cultura com pretensão de esgotá-la enquanto um inventário de componentes. As duas dimensões carregam a arbitrária tarefa de delimitar, precisar, separar e definir.
} 
aos teóricos críticos às abordagens ontológicas. Resta-nos refletir se tal ira reside no âmbito da incompreensão teórica ou simplesmente no ato político deliberado (afinal, crer na teorização não ontológica exige do militante uma reinvenção do discurso).

Entre os anos de 1995 e 1996 foi possível assistir um debate que acrescentou muito aos intermediadores e leitores. A revista Transactions of the Institute of British Geographers, que publicou em 1995 "There's No Such Thing as Culture: Towards a Reconceptualization of the Idea of Culture in Geography" de Mitchell, nos brindou com os artigos-resposta de Cosgrove (1996), Jackson (1996) e James e Nancy Duncan (1996). Tivemos ainda a chance de termos a tréplica de Don Mitchell (1996) publicada no mesmo ano. Destacaremos alguns dos principais pontos do debate:

I) Peter Jackson (1996)

- Faz no seu artigo-resposta uma autocrítica sobre o uso indevido da palavra "meio" ou "domínio" quando se quer falar sobre cultura. Estas palavras sugerem delimitação e seriam indicativos da abordagem ontológica da cultura. Concorda neste aspecto com Mitchell: "Contudo, aceito que as metáforas de domínio, nível, meio e arena mantêm suas próprias cargas ideológicas e reificam "cultura" a um grau que agora eu acharia inaceitável" (Jackson, 2008, p.104);

- Acredita que exista certa materialidade na cultura, dando a entender que o posicionamento de Mitchell (1995) é radical. Argumenta que o que definimos convencionalmente como cultura ganha muito de seu poder a partir de sua materialidade aparente (tanto quanto raça ganha seu poder ideológico a partir de seu enraizamento aparente na natureza). Em suas palavras, "sem tal preocupação pelo mundo material, arriscamo-nos a produzir uma geografia cultural anêmica, onde as únicas lutas são sobre a linguagem e políticas de representação" (Jackson, 2008, p.104);

- Teme que o argumento central de Mitchell possa servir como discurso para opressores mal intencionados, interessados e manter o status quo social: afinal, como assevera Mitchell (1995), a cultura é uma ferramenta política a favor da manutenção do arranjo social, e, portanto, da paisagem. Jackson teme que a negação ontológica radical da cultura sirva como discurso conservador (Jackson, 2008).

II) Denis Cosgrove (1996)

- Discorda de Mitchell acerca do fato de novos geógrafos culturais estarem obcecados em melhorar a definição de cultura, sem que este esforço traga o conceito para fora de uma abordagem ontológica. Alega que Mitchell citou autores sem que tenha compreendido a verdadeira intenção dos mesmos (Cosgrove, 1996);

- Defende a ideia de que as metáforas que se associam a espacialidade, tais como nível, meio, domínio ou arena não precisam de um apoio teórico para serem adequadas a se referirem à cultura. Cosgrove assevera que "uma metáfora é um artifício linguístico - uma construção retórica desenvolvida e desdobrada dentro de uma argumentação persuasiva, não uma técnica de explanação científica" (Cosgrove, 2008, p.108). Mitchell acredita que muitas destas metáforas servem para reificar a cultura, por esta razão sugere a necessidade de que a metáforas sejam embasadas teoricamente. Por serem palavras não literais, podem dificultar a comunicação entre o autor e o leitor do texto, sobretudo no caso de um conceito caótico 
como o de cultura (Mitchell, 1995). Hoefle (2008) concorda com o ponto de vista de Cosgrove (1996), ao afirmar que o conceito de "cultura", como também o de "economia" ou o de "política", são todas abstrações intelectuais construídas para entender outra abstração: a "sociedade". Para Hoefle", "somente um radical empiricista como Mitchell sustenta um debate meramente ontológico, assumindo que "cultura" não tem existência em si, sendo apenas uma construção ideológica" (HOEFLE, 2008, p.131).

III)

James e Nancy Duncan

- Alegam que Mitchell indevidamente quer separar as ideias das práticas materiais. Os autores acreditam que exista indissociabilidade entre esses elementos. Os Duncan acreditam que as ideias são reais, assim como as suas consequências. Utilizam para tanto o exemplo abordado por Mitchell (1995), a raça, reforçando que "não é uma categoria científica legítima, mas que o racismo certamente existe. Os racistas desdobram a categoria raça e consequências muito reais resultam disto" (Duncan e Duncan, 2008, p.111);

- Acreditam que Mitchell (1995) acaba sendo mais tolerante com certas abordagens ontológicas da cultura do que com outras. Para tanto, utilizam as diferenças na abordagem de Mitchell quanto à Raymond Williams e à Zukin, que tratariam a cultura de uma forma muito semelhante e próxima ao sentido ontológico que tanto critica;

- Concordam com Mitchell (1995) quando o mesmo afirma que "a cultura é um termo escorregadio, difícil de definir, que os geógrafos culturais deveriam dar mais atenção ao problema de seu status ontológico e que sempre há o perigo de reificá-la, dando-lhe poderes causais" (Duncan e Duncan, 2008, p.115).

IV) A tréplica de Don Mitchell (1996)

- Discorda de Cosgrove (1996) ao afirmar que as metáforas - especialmente aquelas que se referem à cultura e que são dotadas de sentido espacial - precisam ser fundamentadas pelo fato de vivermos em um mundo social, em que a linguagem pode nos reservar armadilhas comunicativas;

- Mantém a posição que Jackson e os Duncans em trabalhos pretéritos não evitaram o problema da reificação da cultura;

- Reconhece que no artigo-resposta Jackson (1996) e os Duncans (1996) concordam com a premissa central de que não existe a cultura enquanto um ente descritível, confessando estar gratificado pelo fato destes autores "agora queiram tornar sua posição tão explícita" (Mitchell, 1996);

- Reconhece que Jackson (1996) tem razão ao afirmar que a ideia trazida em seu artigo provocador (Mitchell, 1995) pode levar ao entendimento equivocado de que exista uma defesa

\footnotetext{
${ }^{4}$ Apesar do verniz de sofisticação crítica do texto de Hoefle (2008), o mesmo dá mostras de uma abordagem reificadora da cultura, não apenas em um mero jogo de palavras e metáforas, mas por intermédio do entendimento processual de gênese e transformação cultural. Argumenta sobre um uso contraditório da ideia de cultura, primeiro ao afirmar que "após longos debates chegaram a um acordo na Antropologia contemporânea para tratar a cultura como um artifício analítico construído para entender a vida em sociedade, não sendo, portanto, uma entidade ontologicamente reificada" (HOEFLE, 2008, p.132). Contraditoriamente complementa que "Da mesma forma, as divisas fenomenais e espaciais, externas e internas da cultura são delimitadas arbitrariamente para analisar as relações intra e interculturais" (Idem). Ora, se existe a pretensão de delimitação cultural, a sua reificação está dada e sua posição teórica está tomada.
} 
da separação plena entre a materialidade e as ideias. Mitchell (1996) acredita, inclusive, que Cosgrove (1996) e os Duncans (1996) justamente foram conduzidos ao equívoco;

- Reforça que não vê a sua abordagem sobre a cultura como contraditória. Em suas palavras: "Só espero que fique claro que a "forma diferente" que precisa ser teorizada não é apenas uma questão de propor uma melhor noção ontológica de cultura" (Mitchell, 2008, p.119);

- Acha injusta a crítica dos Duncans (1996) acerca da possibilidade de considerar os teóricos culturais, dentre eles os geógrafos, de irreais sobre qual é exatamente seu objeto de estudo. Elucida a suposta má compreensão dos Duncans ao afirmar que "os geógrafos (e outros teóricos culturais) citam continuamente noções reificadas de cultura mesmo quando não é essa a sua intenção e, por esse motivo, reificam a cultura em entidades distintas e delimitadas" (Mitchell, 2008, p.120).

O debate entre estes autores de grande renome nos estudos culturais representou um avanço na reflexão que envolve cultura e espaço, deixando importantes contribuições para a reflexão da paisagem e do lugar. Entre eles, um ponto consensual é que a abordagem ontológica da cultura é inadequada ${ }^{5}$. Nesse sentido, o texto de Mitchell (1995) representou um marco para a geografia cultural, pois despertou e agitou a discussão em torno dessa problemática. Anssi Paasi (2003), sete anos após o quid pro quo, escreveu um artigo sobre região e lugar que versava, principalmente, sobre o conceito de identidade regional. Mesmo sem entrar no mérito da discussão Mitchell-JacksonCosgrove-Duncans, Paasi apresenta uma abordagem não-ontológica sobre as identidades, que passa por fundamentos muito semelhantes aos discutidos pelo quinteto.

Em sua reflexão metodológica sobre a identidade regional, Paasi (2003) argumenta que uma das maiores dificuldades que se associa ao fato de escrever ou falar sobre a identidade regional é que estes atos criam, concomitantemente, uma agenda para entender a sua essência. Utilizando-se de Bourdieu (1999), Paasi (2003) argumenta que palavras tem o poder de produzir "coisas", criar fantasias, fobias, ou simplesmente imagens equivocadas. O autor considera ainda que o conhecimento humano é baseado na identificação e classificação. Este fato acaba por gerar demandas, no senso comum e na academia, por rótulos e imagens simplificadas que tornam menos dolorosa a tarefa comunicativa. Indo na contramão da abordagem ontológica da identidade regional, Paasi salienta que, dentro desta temática, "outro problema é a suposição implícita e muito comum de que a identidade regional é um fenômeno empiricamente existente em uma dada região e que pode ser adequadamente analisado utilizando-se um corpo específico de materiais de pesquisa" (Paasi, 2003, p.480). Neste trecho, especificamente, Paasi nega a tangibilidade da identidade regional.

As reminiscências do debate Mitchell-Jackson-Cosgrove-Duncans se fazem presentes na geografia contemporânea. Apesar de ter sido traduzido em língua portuguesa graças a uma iniciativa da revista Espaço e Cultura da UERJ, o debate em tela não é recorrente em publicações brasileiras. Isto nos leva a crer que a importância desse debate foi subvalorizado no seio da geografia cultural brasileira. Por outro lado, dentre os intelectuais da Geografia Humanista é corriqueiro perceber em seus métodos a presunção de que a ontologização cultural é inadequada. O foco do pensamento no indivíduo, o exercício da alteridade e a pesquisa fenomenológica já presumem que os vícios da abordagem ontológica da cultura tenham sido superados. Avaliamos, entretanto, que o resgate e

\footnotetext{
${ }^{5}$ Cosgrove (1996), por meio de sua crítica, argumenta que aquilo que Mitchell chama de abordagem ontológica se faz necessário como um artifício linguístico, como vimos. Dessa forma, acredita que Mitchell desconsiderou as intenções de quem usou metáforas vistas como reificadoras da cultura.
} 
avanço deste debate é necessário na geografia brasileira. Afinal, a ausência dessas discussões pode continuar perpetuando noções já superadas no ensino básico e também na academia.

\section{O "social" versus o "cultural"}

Como vimos, a chamada "virada cultural" que se desenvolveu na década de 1970 destacou-se pelo foco dado à construção de identidades. Por outro lado, as relações sociais amparadas pelas normas, códigos de comportamento, sentimentos e valores morais ficaram legadas a um segundo plano (Jackson, 1997) em sua abordagem. Foi marcada também pela crença de que o debate cultural é o locus privilegiado do anúncio das inadequações das formas marxistas de explicação social, além da oposição ao quantitativismo positivista. Para Barnett (2004), os argumentos identificados com a virada cultural são fortemente dependentes da crítica pós-modernista acerca das epistemologias totalizantes e essencialistas, das quais o marxismo - taxado de economicista, reducionista, determinista e baseado em classes - é um suspeito primário. Por outro lado, é comumente dito que a virada cultural marginalizou a geografia social e perdeu consistência política ${ }^{6}$ (Valentine, 2001), percepção que pode ter fomentado a guinada em direção à abordagem social dos anos 1980. Em uma crítica ampla à virada cultural, Gill Valentine assevera

Os críticos à virada cultural argumentam que a abordagem centrada em significados, identidade e representações talvez tenham conduzido geógrafos a perder a referência das consequências e efeitos muito reais das identidades sociais e processos, ignorando a economia política da diferença e as relações de poder (VALENTINE, 2001, p.168).

A Nova Geografia Cultural surge no espaço destas críticas e ganhou força nos anos 1980 a partir das publicações de autores como Peter Jackson, Denis Cosgrove, e James Duncan. Desvinculou-se da preocupação da constituição das identidades, centrando-se no entendimento da produção simbólica e em seu papel em ordenar o espaço. Em contraste com a tradicional geografia cultural americana que se tornou alvo de suas críticas, a nova geografia cultural "estava fortemente ligada à sociologia e à geografia britânica e apresentando-se profundamente preocupada com as questões ligadas ao espaço, relações de poder e a diversidade cultural das práticas cotidianas" (SCOTT, 2004, p.24). Para Tim Cresswell (2010), a nova geografia cultural que teve "o seu chamado à guerra" (call to arms) em meados da década de 1980, trata-se de um projeto inacabado. Este status não é explicado por alguma deficiência teórica em seus pressupostos, mas pelo fato do mundo ser marcado pelas desigualdades e injustiças e ainda existir o motivo da academia ser o espaço de denúncia e se constituir como ferramenta de conscientização, numa crítica que nos lembra da icônica obra de Yves Lacoste (2005). Quanto utiliza a palavra injustiça, Cresswell refere-se "ao tipo que envolve a sistemática assimetria de arranjo de poder que permitem a ocorrência da opressão e exploração" (CRESSWELL, 2010, p.172).

Heidi Scott (2004) destaca que a nova geografia cultural foi desenvolvida e abordada por diversos geógrafos fora do Reino Unido, estando, contudo, represada quase exclusivamente no mundo anglófono. O debate visto entre Mitchell (1995) e autores identificados com a Nova Geografia Cultural como Jackson e Cosgrove pode transmitir uma impressão deficiente: a ideia acerca de um disseminado antagonismo entre as características comuns da virada cultural e da Nova Geografia

\footnotetext{
${ }^{6}$ A dita geografia cultural tradicional também sofreu críticas similares àquelas que foram observadas na virada cultural. Geógrafos sociais, sobretudo na Alemanha, classificaram o período morfológico que tem em Otto Schlüter e Sauer expoentes como um momento estéril, que representou em "verdadeiro empecilho para o desenvolvimento da Geografia Social" (SEEMANN, 2004, p.73).
} 
Cultural. Sabe-se que ambas compartilham similitudes, tais como a influência da escola feminista, do pós-estruturalismo, do pós-modernismo e da teoria pós-colonial ${ }^{7}$ (Scott, 2004). As diferenças centradas nos objetos de investigação dos pesquisadores culturais é que, principalmente, possibilitaram a criação destes rótulos. Para ilustrar o fato, Denis Cosgrove, como já foi dito, rejeitou as fáceis associações do seu nome com o rótulo da Nova Geografia Cultural (Cosgrove, 1993). Encaixar intelectuais nestes rótulos torna-se, inclusive, paradoxal às perspectivas pós-estruturalistas que os sustentam, justamente pelo fato desta ação desconsiderar as estruturas híbridas de pensamento. Contudo, isto não representou consenso dentro da discussão cultural do final do século $X X$. As divergências de foco daqueles que, por um lado, centravam-se nas identidades e na discussão sobre significado (chegando ao ponto de Mitchell cravar que a cultura não existe da forma em que entendemos) e, por outro, nas questões sociais mais amplas e nas relações de poder movimentaram críticas, réplicas e tréplicas nas principais revistas e fóruns de discussão nos Estados Unidos e Reino Unido.

Este se tornou um debate infindável dentro da Geografia Cultural. Mesmo posicionando-se no campo de pesquisa sobre o consumo e o comportamento consumista, Peter Jackson alerta que "precisamos transcender o dualismo existente entre o "econômico" e o "cultural" se quisermos fazer sérios progressos na compreensão das culturas comerciais e sua associação com as formas materiais" (JACKSON, 1997, p.187), mostrando que a abordagem radical que apartou temas e métodos assumindo em alguns casos tons partidários na academia é mais nociva do que útil. É importante notar que a oposição ao marxismo característica da virada cultural fez com que alguns autores da Nova Geografia Cultural pudessem ser alvos de críticas $^{8}$, o que nos mostra que os rótulos muitas vezes colaboram para a incompreensão: existem gradações que variam do mais grosseiro ao mais sutil no que diz respeito às apropriações teóricas, o que garante a existência de formas híbridas do pensar.

A discussão a respeito do entendimento da cultura presente no embate Mitchell-JacksonCosgrove-Duncans teve como um dos seus focos a oposição entre ideias e materialidade. Dentro deste escopo, a categoria raça foi analogamente posicionada como a categoria cultura, no que diz respeito à reflexão entre conceitos imateriais e materiais. É uma discussão que possui partidários em ambas as frentes. Guimarães (2002), na mesma linha que os Duncans (1996), acredita que o termo raça é inadequado para apontar as diferenças de cor, mas que o racismo ${ }^{9}$ se pratica por intermédio desta categoria. Paul Gilroy (1998), por sua vez, declara-se contrário à utilização da palavra raça, negando a sua materialidade. Sua posição é endossada pelos seguintes argumentos:

- No tocante à espécie humana não existem raças biológicas;

- O conceito de raça é parte de um discurso científico errôneo e de um discurso político racista, autoritário, anti-igualitário e antidemocrático;

\footnotetext{
${ }^{7}$ A virada cultural desenvolveu-se em anos de muita efervescência teórica. O feminismo, o pós-estruturalismo, o pósmodernismo e a teoria pós-colonial apresentam-se como intertextos da Nova Geografia Cultural, contribuindo para o rompimento com a tradição saueriana (Duncan, 1980). Com o foco nas representações, a Nova Geografia Cultural vê, recentemente, as teorias não representacionais antagonizarem de forma mais notável com os seus pressupostos.

8 Justamente por serem taxados de marxistas.

${ }^{9} \mathrm{Na}$ linguagem diária, na imprensa e mesmo na literatura especializada, a palavra racismo tem muitos significados diferentes, ainda que correlatos. Racismo, em primeiro lugar, é referido como sendo uma doutrina, quer se queira científica, quer não, que prega a existência de raças humanas, com diferentes qualidades e habilidades, ordenadas de tal modo que as raças formem um gradiente hierárquico de qualidades morais, psicológicas, físicas e intelectuais. Mesmo entre os que aceitam esta acepção de racismo qua doutrina, pode-se, ainda, distinguir aqueles para quem a simples crença em raças humanas já constitui racismo e aqueloutros para quem tal crença é tida apenas como racialismo, chamando estes últimos de racismo tão-somente as doutrinas que pregam a superioridade ou inferioridade das raças (Guimarães, 2004, p.17).
} 
- O uso do termo "raça" apenas reifica uma categoria política abusiva.

Assim se desenha divergências que podem ser grosseiramente descritas em suas extremidades: por um lado, aqueles que se opõem ao uso do conceito de raça pelas ciências sociais. Estes se baseiam na negativa da biologia de conceber raças humanas ou na consideração de que esta noção é tão impregnada de ideologias opressivas que o seu uso não poderia ter outra serventia senão perpetuar e reificar as justificativas naturalistas para as desigualdades entre os grupos humanos. Por outro lado, a crença de que seja possível construir um conceito de raça propriamente sociológico, que prescinda de qualquer fundamentação natural, objetiva ou biológica (Guimarães, 2009). Para Guimarães (2009, p.22), somente "uma definição nominalista de raça seria capaz de evitar o paradoxo de empregar-se de modo crítico (científico) uma noção cuja principal razão de ser é justificar uma ordem acrítica (ideológica)".

As palavras raça e cultura reúnem muitas coincidências. Ambas enfrentam essa discussão que envolve a sua materialidade/imaterialidade. A abordagem ontológica de ambas categorias não se sustenta no aspecto visível, tangível. O uso material destas categorias conduz, deliberadamente ou em um nível subliminar, à política. Como nos lembra Mitchell (1996): a cultura serve como um instrumento para ordenar, dominar e, talvez resistir. O mesmo pode ser dito sobre a categoria raça.

Posicionamo-nos como Paul Gilroy (1998), ao acreditarmos que o uso da palavra raça reifica uma categoria política abusiva. Enquanto houver a reificação da raça, o homem comum continuará misturando ideias e materialidade e verá sentido na diferença entre indivíduos. Entendemos, contudo, que a utilização da palavra raça favorece àqueles que se sentem prejudicados socialmente pelo estado das coisas e que serve como delimitador - ainda que tênue - da contemplação de políticas governamentais. Entretanto, esse caminho reforça a diferença. Nosso posicionamento parece ser mais fácil de ser adotado por àqueles que não estão na posição de sofrer os efeitos diretos do racismo, ainda que Paul Gilroy, no seu caso específico, se declare negro.

A utilização ontológica da palavra cultura pode favorecer ao conservadorismo e a manutenção do arranjo social. Explicações causais que levam em conta uma suposta constituição cultural, tangível e descritível, desenham a atuação de uma superestrutura homogeneizadora de comportamentos e servem para o conformismo quanto ao status quo social. Por outro lado, o uso da palavra cultura no sentido ontológico, pode favorecer também a resistência de certas práticas e mesmo identificar certas coletividades como coesas e merecedoras de demarcações de terra e políticas governamentais, como no caso das populações quilombolas e indíg enas.

A utilização ontológica das palavras raça e cultura se justificam por meio das relações sociais de poder, que, em um nível subliminar do entendimento, se reproduzem pelo senso comum. Os opressores de hoje podem ser os oprimidos de amanhã, ainda que as sequelas históricas das relações de poder diacronicamente experimentadas não nos permitam sugerir repetições cíclicas. A história mantém a sua narrativa, com elementos diferentes que a enriquece. Sendo assim, a abordagem ontológica da raça e da cultura serve à militância. Assim sendo, qual o sentido do intelectual apartidário em utilizá-las?

Mesmo em seu texto elegante e furioso contido na obra Os Condenados da Terra, Frantz Fanon (2005), crítico ácido da colonização, desconstruiu a oposição bem versus mal, comumente utilizada no embate entre oprimidos e opressores:

O olhar que o colonizado lança sobre a cidade do colono é um olhar de luxúria, de inveja. Sonhos de posse. Todos os modos de posse: sentar-se à mesa do colono, deitar-se na cama do colono, se possível com a mulher dele. O colono não ignora isso e, constata amargamente 
e sempre em alerta: "Eles querem o nosso lugar". É verdade, não há um colonizado que não sonhe, ao menos uma vez por dia, instalar-se no lugar do colono (FANON, 2005, p.56).

A fórmula é repetida em Pele Negra Máscaras Brancas, obra na qual Fanon argumenta que "o negro quer ser branco" (Fanon, 2008, p.27), referindo-se não a cor propriamente dita, mas a posição que o branco ocupa, entendimento que fica claro quando se expressa: "alguns negros querem, custe o que custar, demonstrar aos brancos a riqueza do seu pensamento, a potência respeitável do seu espírito" (Fanon, 2008, p.27). São estes mecanismos de empoderamento, que alçam o indivíduo em outro equilíbrio na balança entre sofrer e exercer a opressão.

Sendo o homem o animal político, muito se explica a partir das relações de poder. Não existem mocinhos e bandidos tais como elegem muitas das narrativas históricas. Desenha-se neste argumento o fato de que a abordagem ontológica da cultura e da raça possui como serventia a militância. Estamos de acordo com Mitchell (1995) e Gilroy (1998) sobre as inconveniências do ato de reificar.

A grande questão que se apresenta é o fato de que a abordagem não ontológica da cultura dificultar as justificativas teóricas para a luta social. Se o cultural não pode ser expresso coletivamente como uma entidade tangível e descritível, de que modo seria possível militar consensualmente em meio a uma miríade de identidades que possuem, por sua vez, demandas ultra pulverizadas?

\section{Considerações finais}

O intenso debate cultural que marcou os anos 1980 e 1990 penetrou na Geografia acadêmica, centrando-se em questões de grande repercussão para o entendimento da relação cultura e espaço e para a pesquisa geográfica como um todo. Movidos pelas novas ideias trazidas por movimentos intelectuais tais como a virada cultural e a Nova Geografia Cultural, geógrafos destacadamente expuseram algumas divergências que celebremente ficaram marcadas na história do pensamento geográfico em sua fase contemporânea.

A primeira divergência foi acerca da abordagem ontológica da cultura. A partir de uma preocupação com significados, Mitchell (1995) simboliza uma gama de geógrafos que critica a reificação cultural. Dentro desta perspectiva, para além da discussão do significado da cultura, o debate traz repercussões para a sua representação espacial (Silva e Costa, 2018a; 2018b). Esta primeira divergência conduz à segunda, que é justamente os distintos equilíbrios entre a abordagem social e a propriamente cultural no campo da Geografia Cultural. A Nova Geografia Cultural mostrouse afeita às questões sociais, mas, em contrapartida, em muitas de suas abordagens, não evitou o vício da ontologização cultural. Por outro lado, as abordagens pós-estruturalistas mais extremistas, que questionam a materialidade dos conceitos, pecam por não transitarem firmemente nas questões sociais.

Entretanto, a negação da abordagem ontológica da cultura não significa necessariamente um descompromisso com a reflexão acerca dos resultados das relações de poder e da opressão. Afinal, mesmo descrentes frente à materialidade da cultura, abordagens não ontológicas podem muito bem enveredar a investigar os resultados da abstração acerca da materialidade. A oposição entre ideias e materialidade nos leva a imaginar que, mesmo que se considere que a materialidade é falaciosa, muitos agem como se ela existisse, produzindo resultados sociais que são tangíveis e passíveis de serem estudados. Nesse sentido, a teoria encontra um aliado muito mais poderoso do que as bases estruturalistas do pensar: é plausível atacar os resultados da injustiça social e da opressão por 
intermédio da desmitificação da materialidade. Por esta razão, não percebemos sentido nesta dicotomia - que em nossa visão é mítica - entre o social e o cultural na abordagem geográfica e quiçá nas humanidades como um todo. Há de se lembrar que mesmo Don Mitchell (1995), visto como um radical teórico, defende a investigação das formas em que as classes dominantes se apropriaram da imagem de uma cultura material e mítica a favor da manutenção de uma ordem social hegemônica. 


\section{Referências}

BARNETT, Clive. 2004. A critique of cultural turn (in): Duncan, James S.; Johnson, Nuala C.; Schein, Richard H. A companion to cultural geography. Malden: Blackwell Publishing Itd.

BHABHA, Homy K. 2013. O local da cultura. Belo Horizonte: editora UFMG.

CAPEL, Horácio. 2013. Neopositivismo e Geografia Quantitativa. (in): Capel, Horacio. Ruptura e continuidade no pensamento geográfico. Maringá: EDUEM.

COHEN, Anthony P. 1993. Culture as identity: An Anthropologist's view. New Literary History, v.24, p.195-209.

CORRÊA, Roberto Lobato; Rosendahl, Zeny. 2011. Sobre Carl Sauer: uma introdução. (in) Corrêa, Roberto Lobato; Rosendahl, Zeny (Orgs.) Sobre Carl Sauer. Rio de Janeiro: Eduerj.

COSGROVE, Denis. 1993. On "the reinvention of Cultural geography" by Price and Lewis. Annals of the Association of American Geographers, v.83, n.3, p.515-517.

COSGROVE, Denis. 1996. Ideas and culture: a response to Mitchell. Transactions of the Institute of British Geographers. V.21, p.574-575.

COSGROVE, Denis. 2008. Idéias e Cultura: uma resposta a Don Mitchell. Espaço e Cultura, UERJ, Edição Comemorativa, p.107-109.

CRESSWELL, Tim. 2010. New cultural geography - an unfinished project? Cultural geographies, v.17, n.2, p.169-174.

DUNCAN, James. 1980. The superorganic in american cultural geography. Annals of the Association of American Geographers. V.70, n², june, p.181-198.

DUNCAN, James; DUNCAN, Nancy. 1996. Reconceptualizing the Idea of Culture in Geography: A Reply to Don Mitchell. Transactions of the Institute of British Geographers. New Series, v.21, n.3, p.576-579.

FANON, Frantz. 2005. Os condenados da Terra. Juiz de Fora: Editora UFJF.

FANON, Frantz. 2008. Pele Negra Máscaras Brancas. Salvador: Editora UFBA.

GUIMARÃES, Antonio Sérgio Alfredo. 2004. Preconceito e Discriminação. São Paulo: Editora 34.

GUIMARÃES, Antonio Sérgio Alfredo. 2009. Racismo e Antirracismo no Brasil. São Paulo, Editora 34.

GILROY, Paul. 1998. Race ends here. Abringdon, Oxford: Ethnic and racial studies, vol. XXXI, n5, pp.838-47.

HOEFLE, Scott William. 2008. Debates recentes na geografia Cultural anglo-americana: uma apreciação antropológica e filosófica. Espaço e Cultura, Edição comemorativa, p.123-135.

JACKSON, Peter. 1996. The idea of culture: a response to Don Mitchell. Transactions of the Institute of British Geographers, v.21, p.572-573.

JACKSON, Peter. 1997. Geography and the cultural turn. Scottish Geographical Magazine. V.113, n.3, p.186-188.

JACKSON, Peter. 2008. A idéia de cultura: uma resposta a Don Mitchell. Espaço e Cultura, UERJ, Edição Comemorativa, p.103-105.

LACOSTE, Yves. 2005. A geografia - isso serve, antes de tudo, para fazer a guerra. Campinas: Papirus. MITCHELL, Don. 1995. There's No Such Thing as Culture: Towards a Reconceptualization of the Idea of Culture in Geography. Transactions of the Institute of British Geographers. New Series, v.20, n.1, p.102-116.

MITCHELL, Don. 1996. Explanation in Cultural Geography: A Reply to Cosgrove, Jackson and the Duncans. Transactions of the Institute of British Geographers. v.21, n.3, p.580-582.

MITCHELL, Don. 2008. Explicação em geografia Cultural: uma resposta a Cosgrove, Jackson e aos Duncans. Espaço e Cultura, UERJ, Edição Comemorativa, p.117-121 
PAASI, Anssi. 2003. Region and place: regional identity in question. Progress in Human Geography, V.27, n.4, p.475-485.

PRICE, Marie; Lewis, Martin. 1993. The Reivention of Cultural Geography. Annals of the Association of American Geographers. V.83, n.1, p.1-17.

SCOTT, Heidi. 2004. Cultural Turns (in): Duncan, James S.; Johnson, Nuala C.; Schein, Richard H. A companion to cultural geography. Malden: Blackwell Publishing Itd.

SEEMANN, Jörn. 2004. A morfologia da paisagem cultural de Otto Schlüter: marcas visíveis da Geografia Cultural. Espaço e Cultura, UERJ, n.17-18, p.65-76, jan-dez.

SILVA, Leonardo Luiz Silveira da; Costa, Alfredo. 2018a. A inadequação das regionalizações culturais mediante os pressupostos do pós-colonialismo. Salvador: Geotextos, v.14, n.1, p.225-247.

SILVA, Leonardo Luiz Silveira da; Costa, Alfredo. 2018b. Cultura como comunidade imaginada: uma crítica à abordagem ontológica da cultura nos estudos geográficos. Geografias, v.26, n.1, p.27-41.

VALENTINE, Gill. 2001. Whatever happened to the social? Reflections on the "cultural turn" in British Human Geography. Norwegian Journal of Geography, v.55, p.166-172. 